\title{
Letter to the editor: comparison of retinal detachment surgery outcome among patients undergoing pars plana vitrectomy with and without relaxing retinotomy
}

\author{
Murat Kucukevcilioglu ${ }^{1}$ Ali Hakan Durukan ${ }^{1}$
}

Received: 23 June 2015 / Accepted: 18 July 2015 /Published online: 1 August 2015

(C) Springer-Verlag Berlin Heidelberg 2015

\section{Dear Editor,}

We read with interest the paper "Comparison of retinal detachment surgery outcome among patients undergoing pars plana vitrectomy with and without relaxing retinotomy" written by Frenkel $\mathrm{T}$ et al. [1]. They reported functional and anatomical outcomes in patients who underwent pars plana vitrectomy for complicated retinal detachment due to various etiologies. They compared the outcomes between pars plana vitrectomy performed without retinotomy and performed with retinotomy. Interestingly, their findings showed that retinotomy itself does not increase the rate of treatment failure or worse outcomes. This may really help clinicians with decision-making when faced with complicated retinal detachments. However, there is no description of the term "complicated retinal detachment", which is mentioned as a limitation of the current study. We think that at least a general description would really improve the understandings of readers. In addition to this, they did not specify the sclerotomy size (20-, 23- or 25-gauge). This really matters, since the rate of complications such as the rate of postoperative hypotony varies among different sclerotomy sizes, and eventually may affect the final outcome $[2,3]$. There were four cases in the

Murat Kucukevcilioglu

eyedrmuratk@gmail.com

1 Department of Ophthalmology, Gulhane Military Medical School, GATA Goz Klinigi, Etlik/Ankara 06010, Turkey vitrectomy plus retinotomy group which developed macular hole after surgery, and were followed up conservatively. We would be keen to know if the authors can share their ideas on the possible mechanisms for macular hole development, and relations with retinotomy. Secondly, what were their objective criteria for not proceeding with macular hole surgery?

Conflict of interest All authors certify that they have NO affiliations with or involvement in any organization or entity with any financial interest (such as honoraria; educational grants; participation in speakers' bureaus; membership, employment, consultancies, stock ownership, or other equity interest; and expert testimony or patent-licensing arrangements), or non-financial interest (such as personal or professional relationships, affiliations, knowledge, or beliefs) in the subject matter or materials discussed in this manuscript.

\section{References}

1. Frenkel T, Moisseiev E, Neudorfer M, Loewenstein A, Barak A (2015) Comparison of retinal detachment surgery outcome among patients undergoing pars plana vitrectomy with and without relaxing retinotomy. Graefes Arch Clin Exp Ophthalmol 253(6):855-864

2. Kim M, Park YS, Lee DH, Kohn HJ, Lee SC, Kim SS (2015) Comparison of surgical outcome of 23-gauge and 25-gauge microincision vitrectomy surgery for management of idiopathic epiretinal membrane in pseudophakic eyes. Retina May 13 [Epub ahead of print]

3. Adelman RA, Parnes AJ, Michalewska Z, Ducournau D, European Vitreo-Retinal Society (EVRS) Retinal Detachment Study Group (2014) Clinical variables associated with failure of retinal detachment repair: the European Vitreo-Retinal Society Retinal Detachment Study Report number 4. Ophthalmology 121(9):17151719 